See Article page 2185 .

\section{Commentary: Why "tri" to repair the valve if it will just "lead" to recurrent regurgitation?}

\author{
Timothy J. Pirolli, MD
}

Life-threatening arrhythmias after congenital heart surgery that require cardiac rhythm devices remain a challenging management problem for many patients. In this report from Huang and colleagues, ${ }^{1}$ the authors examine midterm results of the surgical management of transvenous lead-induced tricuspid regurgitation. The authors determine that there are similar rates of survival and reintervention on the tricuspid valve between the valve repair and valve replacement cohorts during their follow-up period. However, their results also demonstrated an impressive amount of progressive tricuspid regurgitation at 5 years in patients who underwent valve repair. The alternative of bioprosthetic valve replacement has been well-established to have early dysfunction due to valve deterioration, especially in younger patients. ${ }^{2}$ Thus, there is no surgical panacea for transvenous lead-induced tricuspid regurgitation, so it is critical to start thinking "outside of the (pacemaker) box" as new techniques and technologies emerge.

It should be emphasized that the cohorts examined involved patients with congenitally "normal" tricuspid valves, excluding patients with congenital tricuspid valve abnormalities (including Ebstein and atrioventricular canal). However, $57 \%$ of the patients had a previous repair of a ventricular septal defect, which may lead to scarring and abnormal tricuspid valve function. In addition, this cohort mainly involved adult patients (median age 48.2 years) who received their initial transvenous cardiac

\footnotetext{
From the Division of Pediatric Cardiothoracic Surgery, Department of Cardiothoracic Surgery, UT Southwestern Medical Center/Children's Medical Center, Dallas, Tex. Disclosures: The author reported no conflicts of interest.

The Journal policy requires editors and reviewers to disclose conflicts of interest and to decline handling or reviewing manuscripts for which they may have a conflict of interest. The editors and reviewers of this article have no conflicts of interest.

Received for publication Nov 30, 2021; revisions received Nov 30, 2021; accepted for publication Dec 1, 2021; available ahead of print Dec 4, 2021.

Address for reprints: Timothy J. Pirolli, MD, Division of Pediatric Cardiothoracic Surgery, UT Southwestern Medical Center/Children's Medical Center, 1935 Medical District Dr, Dallas, TX 75235 (E-mail: Timothy.Pirolli@ UTSouthwestern.edu).

J Thorac Cardiovasc Surg 2022;163:2196-7

$0022-5223 / \$ 36.00$

Copyright (c) 2021 by The American Association for Thoracic Surgery

https://doi.org/10.1016/j.jtcvs.2021.12.002
}

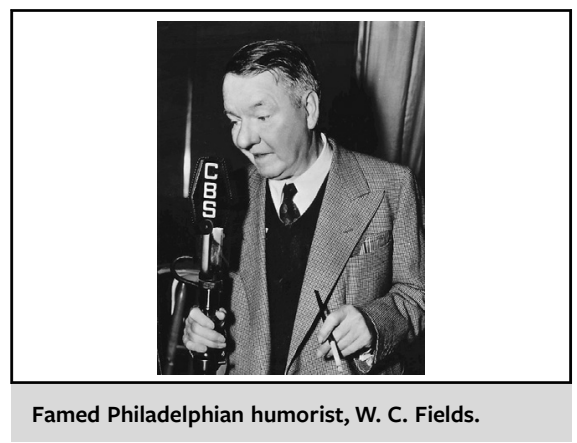

CENTRAL MESSAGE

With no long-term advantage to

tricuspid valve repair and new

evolving technologies emerging:

"All things considered, l'd rather

replace the valve."

rhythm device after somatic growth was complete (median age 39.5 years). Theoretically, if there was any subset of patients with lead-induced tricuspid regurgitation who were amenable to durable repair of the valve, this would be this cohort. Yet with a $74.4 \%$ recurrence of moderate-severe TR in the repair group at 5 years, it appears that this hypothesis does not hold true. Therefore, the ubiquitous mentality of "repair the valve first, if feasible" may not apply to this lead-induced tricuspid regurgitation population.

So, if the valve repair option is suboptimal, should valve replacement be the standard of care? If so, what measures can be taken when the prosthetic valve or the leads fail? Recent advances in transcatheter tricuspid valve replacement in the setting of transvenous leads have shown promise as a safe alternative to surgical tricuspid valve rereplacement. ${ }^{3}$ Also, placement of the transvenous RV lead(s) in a paravalvar position during the time of surgical tricuspid valve replacement as performed by the authors of this report and others has become a popular alternative to conventional placement of the transvenous leads across the prosthetic valve orifice. ${ }^{4}$ This technique could decrease the rapidity of valve failure and may allow for easier lead removal, if needed. The development of a leadless pacemaker system should also prove beneficial, as placement of this system after tricuspid valve surgery has shown early promise to be a safe and feasible option to traditional transvenous lead pacing systems. ${ }^{5}$ 
Regardless of the approach, an $80.4 \%$ survival at 5 years is sobering and emphasizes the potentially ominous nature of lead-induced tricuspid regurgitation requiring surgical intervention. So, as a native Philadelphian, I conclude with a paraphrase of the commonly misquoted W. C. Fields fictional epitaph: "All things considered, I'd rather replace the valve."

\section{References}

1. Huang Y, Dearani JA, Lahr BD, Stephens EH, Madhavan M, Cannon BC, et al. Surgical management of transvenous lead-induced tricuspid regurgitation in adult and pediatric patients with congenital heart disease. $J$ Thorac Cardiovasc Surg. 2022;163:2185-93.e4.

2. Burri M, Vogt MO, Horer J, Cleuziou J, Kasnar-Samprec J, Kuhn A, et al Durability of bioprostheses for the tricuspid valve in patients with congenital heart disease. Eur J Cardiothorac Surg. 2016;50:988-93.

3. Anderson JH, McElhinney DB, Aboulhosn J, Zhang Y, Ribichini F, Eicken A, et al Management and outcomes of transvenous pacing leads in patients undergoing transcatheter tricuspid valve replacement. JACC Cardiovasc Interv. 2020;13: 2012-20.

4. Michaelis A, Wagner F, Riede F, Schroeter T, Daehmert I, Pfannmueller B, et al Performance of pacemaker leads in alternative lead positions after tricuspid valve replacement. Pacing Clin Electrophysiol. 2020;43:1382-9.

5. Theis C, Huber C, Kaesemann P, Kaiser B, Heinrick H, Albert M, et al Implantation of leadless pacing systems in patients early after tricuspid valve surgery: a feasible option. Pacing Clin Electrophysiol. 2020;12:1486-90. 